\title{
COMMUNICATION MODELS AND COMMON BASIS FOR MULTICULTURAL COMMUNICATION IN LATVIA
}

\author{
Andris Petersons \\ Turiba University, Latvia \\ Ilkhom Khalimzoda \\ Turiba University, Latvia
}

\begin{abstract}
Different models serve not only as a frame for communication, they can help to rise problems as well as discuss them. This article introduces with the four communication models starting from Aristotle's triangle model and ending with a more contemporary one. The authors try to find out, which is the most appropriate model for intercultural communication in Latvia? The empirical data collected from two focus-groups representing different cultures in Latvia serves as a base for interpretation of current situation where communication challenges can occur as a result of interaction between people with different cultural backgrounds. The article approves the idea to elaborate the new specific model for multicultural communication, and after analysis highlights the base and components of this new model.
\end{abstract}

Keywords: communication, models, multiculturalism, cultural differences, elements of communication.

\section{Introduction}

Almost any organization in Latvia has to deal with employees, partners or clients from different cultures. Such condition can pose challenges, but at the same time it can be beneficial. In a global and a diverse world, we can leverage these advantages and mitigate the risks through both awareness and complexity of communication. Communication models from dominant to alternative ones are being discussed and used continuously, but the problem occurs when we try to implement the specific communication model in the selected group of people with different backgrounds. The lack of awareness about communication models and the absence of multicultural communication competence could be the reasons why people from different cultures in Latvia annoy each other and cannot find a common language. Question of research: How to overcome cultural differences in communication using models of communication? In order to create the new specific model of multicultural communication, authors highlight the different communication models and examine their usage between people with different cultural backgrounds. 
Andris Petersons, Ilkhom Khalimzoda. Communication Models and Common Basis for Multicultural Communication in Latvia

Communication is not only transportation of messages, nowadays communication is more of sharing ideas and feelings and willingness to participate. Ancient Greek philosopher Aristotle provides an explanation of communication that is still worthy of attention. His study of communication called „rhetoric" speaks about the elements within the process. Aristotle provides us with this insight: rhetoric falls into three divisions, determined by the three classes of listeners to speeches. For the three elements in speech-making - speaker, subject, and person addressed - it is the last one, the hearer that determines the speech's end and object (Aristotle, 350 BC: part 3). Here Aristotle speaks of a communication process composed of a speaker, a message and a listener. Note, he points out that the person at the end of the communication process holds the key whether or not communication takes place. Since Aristotle the communication process has been studied by many promoters of models. They designed certain formats adapted to different situations and types of communication. The use of models allows the interpretation of phenomena using certain structures that link the elements and relationships that can exist between these elements. (Popescu, Pargaru, Popescu, Mihai, 2015:65) They are vitally necessary because both biological and social life of society exists through a process of transmission. Without the communication of ideals, hopes, expectations and practices from those members of society who are passing out of the group life to those who are coming into it, social life could not survive. It makes communication both pleasant and essential. The famous communication scholar from US Joseph DeVito accounted at least five main reasons why we communicate. They are: 1) to influence people, 2) to establish/maintain interpersonal relationships, 3) to acquire knowledge, 4) to help people, 5) to play. (DeVito, 2013: 11). The authors of communication's definitions have tried to say something unique about this process in which messages are sent and received with a specific aim via communication channels through noise which envelops the communication channels, the sender and receiver and feedback. The communication is primarily understood in the sense of transmission. (McQuail, 2005:26). However, the professor emeritus from University of Amsterdam Dennis McQuail agrees with the idea of American philosopher John Dewey that there is more than a verbal tie between the words in common, community, and communication. People efforts to put communication into a precise frame led to development of communication models. At the core of modeling is the fundamental notion, that models are approximations of the real world. (Sokolowski J.A., Banks C.M., 2010:1). In this very first step in modeling, model is created according to the real world, and vice versa - model can be modified after testing. 


\section{Aristotle Model of Communication}

According to Aristotle, the speaker plays a key role in communication. He is the one who takes complete charge of the communication. The sender first prepares a content which he does by carefully putting his thoughts in words with an objective of influencing the listeners or the recipients, who would then respond in the sender's desired way. No points in guessing that the content has to be very impressive in this model for the audience or the receivers to get convinced. The model says that the speaker communicates in such way that the listeners get influenced and respond accordingly (Aristotle, $350 \mathrm{BC}$, part 3).

The speaker must be very careful about his selection of words in this model of communication. In other words, think before you act, as advices DeVito (DeVito, 2013:20). Speaker would explore the target audience and then prepare his speech. For example, the politician must understand the needs of the people in his constituency like the need of a shopping mall, better transport system, safety of society and then design his speech. The speech should address all the above issues and focus on providing the solutions to their problems to expect maximum votes from them. His tone and pitch should also be loud and clear enough for the people to hear and understand the speech properly. Stammering, getting nervous in between of a conversation must be avoided. Voice modulations also play a very important role in creating the desired effect. Blank expressions, confused looks and similar pitch all through the speech make it monotonous and nullify its effect. The speaker should know where to lay more stress on, highlight which words to influence listeners. One will definitely purchase the mobile handset from that store where the salesman gives an impressive demo of the mobile. It depends on the salesman what to speak and how to speak in a manner to influence the listeners so that they respond to him in a way he actually wants i.e. purchase the handset and increase his billing. The Aristotle model of communication is the widely accepted and the most common model of communication where the sender sends the information or a message to the receivers to influence them and make them respond and act accordingly. Aristotle model of communication is the golden rule to excel in public speaking, seminars, lectures where the sender makes his point clear by designing an impressive content, passing on the message to the second part and they simply respond accordingly. Here the sender is the active member and the receiver is passive one.

\section{Shannon and Weaver's Model of Communication}

This model was introduced in the middle of the last century, is particularly designed to develop the effective communication between sender and receiver. This is however, a model of signal processing. Shannon and Weaver did not rise 
the question of the content or message that was transferred. They found factors which affects the communication process called "Noise", but the model also deals with various concepts like information source, transmitter, noise, channel, message, receiver, channel, information destination, encode and decode. In this model the sender is the originator of message or the information source selects the desired message. Encoder is the transmitter which converts the message into signals (Shannon, Weaver, 1948:380). Nowadays with "converting" we understand not only signals like waves or binary data which are compact-able to transmit the messages through cables or satellites, but usage of words, symbols and signs to express an idea. If the message is distracted by noise, it will affect the communication flow between sender and receiver. During this process the messages might be distracted or affected by physical noise like sounds, thunder and crowd noise or encoded signals may distract in the channel during the transmission process which affect the communication flow or the receiver may not receive the correct message. Despite on latest findings of Joseph DeVito, who divides noise into four parts: physical noise, physiological noise, psychological noise and semantic noise (DeVito, 2013:8), the Shannon and Weaver model clearly deals with external noises which affect the messages or signals from external sources. This model helps us to understand the components, their role and structure of communication.

\section{Berlo's Model of Communication}

While the Aristotle model of communication puts the speaker in the central position and suggests that the speaker is one who drives the entire communication, the Berlo's model of communication takes into account the different aspects of the message (content, elements, treatment, structure, code) and equalizes both sender and receiver. Berlo's model of communication operates on the SMCR pattern (Berlo, 1960: 124). In the SMCR pattern S - Source; M - Message; C Channel; R - Receiver; the source also called the sender is the one from whom the thought originates. Sender transfers the information to the receiver carefully placing his ideas into words. The ideal communication occurs when both sender and receiver have the common expertise in communication skills, the same attitude, knowledge, social system and culture. These factors play a significant role in the communication process and level of encoding and decoding. Berlo's model differs from Shannon and Weaver's model mostly because it emphasizes the common understanding, which is significant part of communication. Despite on the criticism of Berlo's model (model leaves no place for feedback, there is no barriers, filters or feedback), it has its own preferences. The most important contribution from Berlo can be the idea that meanings are not in the message, they 
are in the message users, and therefore communicators must be explored from perspective of their background.

\section{Schramm's Interactive Model of Communication}

In his Circular Model Schramm embodied idea that communication is a circular process by nature. Schramm conceived of decoding and encoding as activities maintained simultaneously by sender and receiver; he also made provisions for a two-way interchange of messages (Schramm, 1961: 5-6). In this model, encoder is who originates and sends the message. Decoder is who receives the message and interpreter could be any person trying to understand and analyze, perceive or interpret. From the starting point of communication to the end an interpretation goes on. This model breaks the traditional sender and receiver models; each person acts as both sender and receiver and hence uses interpretation. Encoding, decoding and interpretation is going on simultaneously. Semantic noise is a concept introduced here when sender and receiver apply different meaning to the same message. It happens mostly because words and phrases are not understandable, so certain words and phrases will cause you to deviate from the actual meaning of communication.

\section{Multiculturalism}

The man of a postmodern age has been rooted in new orders determining his/her everyday reality, where existence involves answering many questions of primal nature, including communication. Alicja Szerlag stresed the role communication into process of understanding and tolerating other cultures (Szerlag, 2015: 137). The definition of culture has long been a controversy because culture as a phenomenon on the object level is constructed in the discursive process by forming various concepts (Budin, Vol.I) . Very popular United Nations Educational, Scientific and Cultural Organization definition considers the culture as complex which includes knowledge, beliefs, morals, laws, customs, and any other capabilities and habits acquired by a human as a member of society. ${ }^{1}$ Center for Advanced Research on Language Acquisition from University of Minnesota for purpose of intercultural studies project defines culture as the shared patterns of behaviors and interactions, cognitive constructs, and affective understanding that are learned through a process of socialization. ${ }^{2}$ It means, the essence of culture is not artifacts, and different tangible cultural elements but how the members of specific group interpret, use, and perceive them.

\footnotetext{
${ }^{1} \mathrm{http}: / /$ www.unesco.org/new/en/social-and-human-sciences/themes/international-migration/glossary/culturaldiversity/

${ }^{2}$ http://www.carla.umn.edu/
} 
It is the values, symbols, interpretations that distinguish people in modern societies. This idea was dominant for Dutch scientist Geert Hofstede to develop his onion model (Hofstede G., Hofstede G.J., 2005;26) If for Michelle LeBaron the culture is like underground river which runs through our lives and relationships, giving us messages that shape our perceptions, attributions, judgments, and ideas of self and other ${ }^{3}$ at the same time, we have to bear in mind than culture is ordinary (Williams, 1958:2). Though culture is powerful, it is often unconscious, influencing conflict and attempts to resolve conflict in imperceptible ways. Culture is more significant than language, costumes and foods. Cultural groups may share race, ethnicity, or nationality, but they also arise from cleavages of generation, socioeconomic class, sexual orientation, ability and disability, political and religious affiliation, language, and gender ${ }^{4}$. Multicultural ideology refers to overall evaluation of the majority group addressing the degree to which they possess positive attitudes toward immigrants and cultural diversity. (ArendsToth, Vijver, 2003: 249-266) Multiculturalism is viewed as a paradox in dealing with the question of how to construct a society that accommodates universal rights with the rights of minority groups. (Dong, Day, Collaco, 2005:27-38). Any group of people consists of individuals, therefore capacity of individual plays the main role in intercultural communication, and different individuals have various values.

These values are communicated through rituals, heroes and symbols. Sometimes, they are as ordinary as a napkin. However, even ordinary symbols can have a powerful influence on relationship and the ultimate success or failure of an encounter. It could easily happen, if one uses the moral standards of one culture to judge the other. That other culture will invariably appear to be morally inferior. (Hofstede, Pedersen., Hofstede, 2002:19-69). The researcher Benjamin M. Cole suggests that high-context communicators utilize content management practices - which alter message content characteristics - and context management practices (Cole, 2015:585) which either rely on, tear at temporarily, or attempt to reprogram more permanently the shared understandings through which messages are being delivered and interpreted.

\section{Key Findings of Focus Group Discussions}

The objective of empirical research was to find out: 1) How different cultural backgrounds can influence the selection of communication model? 2) Which components of models are primary for multicultural communication, and how the specific model of multicultural communication should look like? Empirical research was conducted from September 10 to September 12, 2015. The focus

\footnotetext{
${ }^{3} \mathrm{http} / / / \mathrm{www} \cdot$ beyondintractability.org/essay/culture-conflict ${ }^{4} \mathrm{http}: / /$ www.beyondintractability.org/essay/culture-conflict
} 
group discussion was chosen as a form of qualitative research to get opinion of representatives of different cultures. Criteria for participation was nationality, legal status (citizens of LR versus non-citizens of LR), and social status. Two focus groups organized according to nationality Latvian and Tajik were gathered with ten participants in each. Participants (in total20 persons) included opinion's leaders, artists, teachers, state social workers, employers and NGO managers. During the two hours 12 significant topics from the communication's field ((1) role of sender, (2) role of receiver (3) role and choice of communication channel, (4) reconciliation of values of sender and receiver, $(5,6,7,8)$ the technical, physical, psysiological, psychological noises, (9) barriers in communication, (10) necessity of feedback, (11) usage of signs and symbols, (12) recognition of models of communication)) similar to both groups were discussed to find out the structure and components of new possible model for intercultural communication.

Authors examined, categorized and indexed the data to make conclusions. Summary of empirical research: all Tajiks and eight of the Latvian participants have a contact with representatives of different cultures every day, two Latvians have contacts less than once in week. All of the participants evaluated their experience in communication with different cultures above mediocre, 3,8 from 5 in average. The main factors influenced the opinion about representatives of different cultures in descending order were the own experience of participants, family, friends, mass media, and politicians. Nine representatives of the Latvian group and all ten representatives of the Tajik group expressed the willingness to learn more about different cultures, the same proportion was indexed for willingness to communicate with representatives of different cultures. 10 Tajik correspondents and 9 Latvians were interested in cooperating and communicating with representatives from other cultures. After analyzing the communication models it came out that Latvians were more stressed in the role of channels and sender in communication but for Tajiks both parts the sender and the receiver played a significant role. Personality of communicator means a lot for both Tajiks and Latvians. Here they totally relied on Aristotle's model. Latvians put charisma and honesty of a partner in the first place, while Tajiks stressed the attitude and leadership. Tajiks are more flexible than Latvians towards using the third language as lingua franca, they are more patient and ready to adapt requirements of communication circumstances. The crucial necessity to provide the dialogue for mutual benefit according to Schramm's model was widely expressed and became undisputable after discussions. 
Andris Petersons, Ilkhom Khalimzoda. Communication Models and Common Basis for Multicultural Communication in Latvia

\section{Combined model of communication between people of different cultural background}

The models mentioned above show the variety of concepts for transferring the message. As far as a choice of model depends on many characteristics, we cannot simply choose the one model and ignore the others. Therefore, the authors were interested to unify concepts from different models for communication in a multicultural environment to justify idea of Tomas Garza that attaining comfort and fluidity in multicultural communication is surprisingly easy (Garza T., 2015: 23 ). The figure 1 below shows how the combination of communication models looks like from the point of authors according to different cultural background of people.

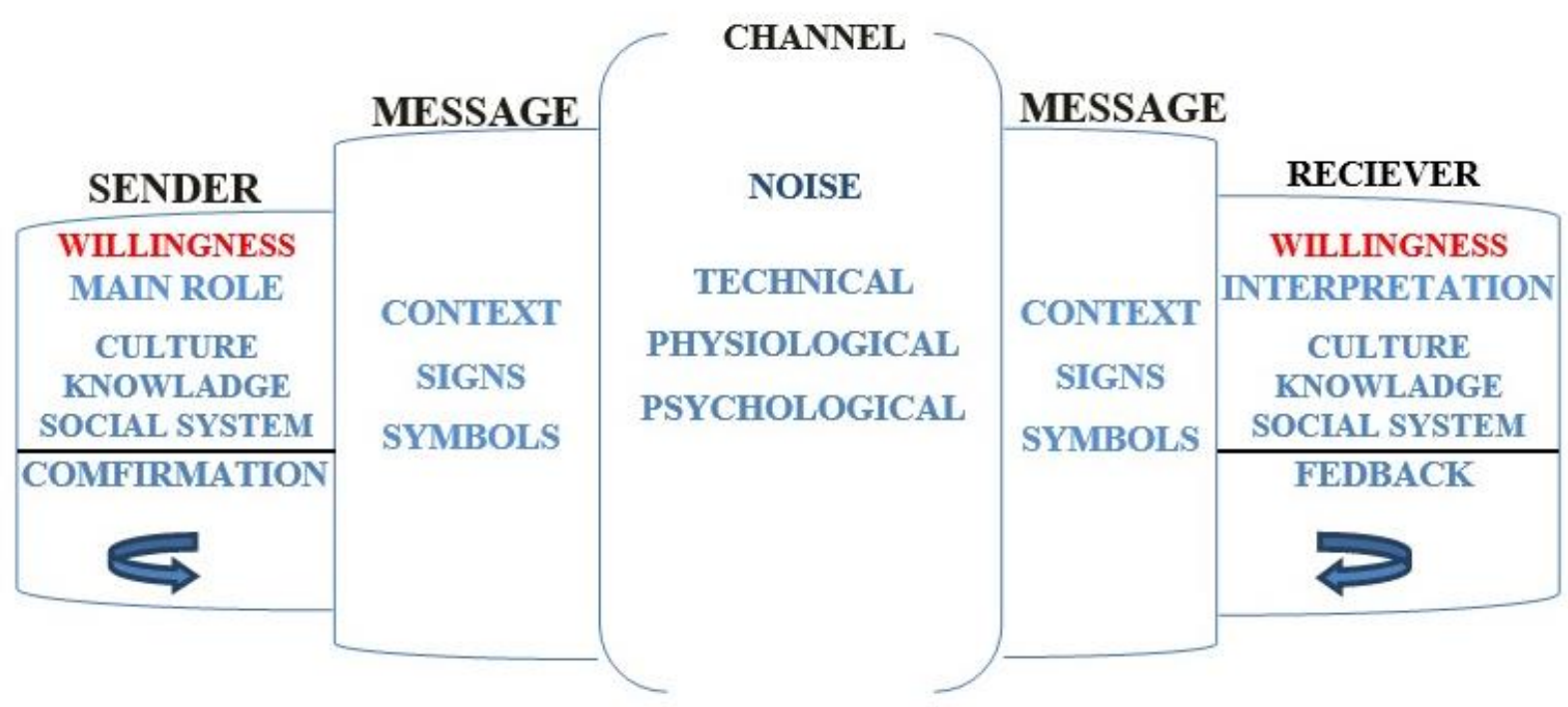

Figure 1 Combined model of communication between people of different cultural background (done by authors)

The sender plays the main role in this model because participants of focus groups admitted the significance of it. This corresponds with the idea of Aristotle. Sender creates the message based on his culture, knowledge, and social system he belongs to. The importance of context is undisputable according to findings of authors. The channel of communication must be chosen adequately in order to avoid noises such as fatigue, bad mood, and lack of time, wrong assumption or reputation. The noise could shape the message and receiver again has to have willingness to interpret it. After getting the immediate feedback sender confirms how received message matches with the original one. The most important components of this model are willingness and conformity from both sides the sender and the receiver. Words in red color indicate the contribution of the authors on the recommended combination model of communication (CMC) in Latvia. Willingness and other elements from the sender's side should minimize the wrong 
encoding and decoding of message. Receiver by interpreting the message reflect its willingness to receive message and correctness of message through feedback to the sender. Then there is a confirmation part which approves the correctness of message and shows the ongoing nature of communication's circle.

\section{Conclusion}

The authors propose the integration of elements from Aristotle's, Berlo's, Shannon \& Weaver's and Scramm's models as the key to succeed in intercultural communication by adding to the model the element of interpretation and confirmation of the feedback. In this combination of the most known models of communication the speaker plays 'main role', because the speaker takes initiative and opens an adequate channel. From the model of Shannon and Weaver authors want emphasize the idea that communication consists of transmitting the messages by using the adequate channel of communication. Unfortunately, the role of personalities and content of message in this model is a minimal. For this reason, communicators should use the model of Berlo to develop these elements. According to Berlo, the role of the receiver is even more significant than the sender but authors, according to the results of focus-groups, consider that the sender has more responsibility to find form, structure and context which allows easy understand the message. By focusing on this, the authors want to stress the role of people and their experience based on cultural background.

Although meanings have always been changing, and two people do not have the same meaning for anything in the most cases, people with similar experience have a privilege to communicate more easily. On the one hand, such experience rises the capacity to communicate with other people, on the other hand, it is absolutely necessary, because the postmodern rhetorical theory claims to take two minds to make truth. One of the biggest mistakes in communication process, according to the focus-group results, is to consider it finished. This gives as straight approve to Schramm's idea that communication naturally has a form of a circle. Circulation from Schramm's model gives us feedback, the interpreted decoding, which is the representation of the meaning received. However, confirmation of the feedback seems necessary to keep the communication ongoing and make sure that the message is understood as it was aimed. The study also showed that leaders emphasized the principles of dialogue, including the willingness to understand the partner, communicator's accuracy, the adequate channel and responsibility of sender of information; but the first of all they stressed the goal of all process. It corresponds with the idea of Anderson (Anderson, 1994:295) that intercultural adaptation is a motivated and goaloriented process. Findings of authors approved the necessity of new, specific 
Andris Petersons, Ilkhom Khalimzoda. Communication Models and Common Basis for Multicultural Communication in Latvia

model of multicultural communication, and provided with information necessary for construction of this model.

\section{References}

Anderson, L.E (1994). A new look at old construct: Cross-cultural adaptation. International Journal of Intercultural Relations, Volume 18, issue 2, 293-328.

Arends-Toth, J., \& Van de Vijver, F. (2003). Multiculturalism and acculturation: Views of Dutch and Turkish-Dutch. European Journal of Social Psychology, 33, 249-266.

Aristotle (350 BC). Rhetoric. Translated by W.Rhys Roberts, The Internet Classic Archive, [revieved 20.04.2015]. http://classics, mit.edu//Aristotle/rhetoric.html

Berlo, D. (1960). The Process of Communication. Holt, Rinehart and Winston Inc., New York.

Budin, G. Theory and History of Culture. Culture, Civilization and Human Society. Vol. 1. http://www.eolss.net/sample-chapters/c04/e6-23-01.pdf [revieved 13.10.2015.]

Center for Advanced Research on Language Acqusition. http://www.carla.umn.edu/ culture/definitions.html [revieved 22.10.2015. 13.10.2015.]

Cole, B. (2015). Lessons from a Martial Arts Dojo: a Prolonged Process Model of High-Context Communication. Academy of Management Journal, Vol. 58. No.2, 567-591.

Cultural diversity. http://www.unesco.org/new/en/social-and-human-sciences/themes/ international-migration/glossary/cultural-diversity/ [revieved 22.10.2015.]

DeVito, J. (2013). Interpersonal Communication Book. Pearson.

Dong, Q., Day, K.D., \& Collaco C.M. (2005). Overcoming Ethnocentrism through Developing Intercultural Communication Sensitivity and Multiculturalism. Human Communication. A Publication of the Pacific and Asian Communication Association. Vol. 11, No.1, 27-38.

Garza, T. (2015). Avoid beig a Cultural Rube: Multicultural communication tips for today's world, Canadian Manager. Winter 2015, Vol. 39 Issue 4, 22-23.

Hofstede, G.J., Pedersen, P.B., \& Hofstede, G. (2002). Exploring Culture, Yarmouth, Maine: Intercultural Press.

Hofstede, G., \& Hofstede, G.J. (2005). Cultures and organizations. Software of the mind. Intercultural Cooperation and Its Importance for Survival. Revised and Expanded 2nd Edition. New York: McGraw-Hall,.

Kim, Y.Y. (2001). Becoming Intercultural. An integrative Theory of Communication and Cross-Cultural Adaptation. Thousand oaks, CA: Sage.

LeBaron, M. (2003). Culture and conflict. http://www.beyondintractability.org/essay/cultureconflict [revieved 22.04.2015.]

May, J., \& Lending, D. (2015). A Conceptual Model For Communicating an Integrated Information Systems Curriculum. Journal of Computer Information Systems. Summer 2015, Vol. 55, Issue 4, 20-27.

McQuail, D. (2005). McQuail's Mass Communication Theory. Sage Publications.

Popescu, D.M, Pargaru, I., Popescu, C., Mihai, D. (2015). A multidisciplinary approach of communication. Theorethical and Applied Economics. 2015, Vol. 22, Issue 2, 65-76.

Shannon, C. (1948). A Mathematical Theory of Communication. Bell System Technical Journal, Vol. 27, 379-423, http://cm.bell-labs.com/cm/ms/what/shannonday/ shannon1948.pdf [revieved 22.04.2015].

Sokolowski, J.A., Banks, C.M. (2010). Modeling and Simulation Fundamentals: Theorethical Underspinnings and Practical Domains, Wiley. 
Szerlag, A. (2012). Socialization Models in Families as the Result of Multicultural Communication. Filosofija, Komunikacija, 2012, Vol. 20, Issue 2, 136-146.

Wilbur, S. (1966). How Communication Works. The Process and Effects of Mass Communication. Urbana, Ill. The University of Illinois Press, pp. 5-6.

Wiliams, R. (1958). Culture is ordinary. http://uk.sagepub.com/sites/default/files/upm-binaries/59594_McGuigan_Raymond_Williams.pdf [revieved 13.10.2015.]. 